\title{
El deterioro del Estado empresario: transformaciones estructurales y desempeño de las empresas públicas argentinas (1976-1983)
}

\author{
The Decline of the Entrepreneur State: \\ Structural Transformations and Performance \\ of Argentine Public Companies (1976-1983)
}

\author{
Ana Gabriela Castellani
}

Instituto de Altos Estudios Sociales de la Universidad Nacional de San Martín, Buenos Aires, Argentina, email: anagcastellani@gmail.com

\author{
Lucas Daniel Iramain \\ Consejo Nacional de Investigaciones Científicas y Técnicas \\ Buenos Aires, Argentina, email: lucasiramain@yahoo.com
}

Resumen. El objetivo del artículo es analizar el desempeño de algunas de las principales firmas públicas durante la última dictadura argentina (1976-1983) en materia de empleo, salarios, productividad, endeudamiento externo, inversión, entre otras. Utilizando fuentes primarias de las empresas estatales y registros estadísticos públicos, se busca demostrar que durante esos años se deterioraron de forma sustantiva las capacidades financieras y técnicooperativas de las compañías públicas como resultado de la instauración de un nuevo régimen de acumulación de capital, basado en la valorización financiera, la privatización periférica, la imposición de disciplina a la clase trabajadora y el cambio en la concepción del Estado-empresario como actor fundamental de la estrategia de desarrollo.

Palabras clave: Estado empresario; empresas públicas; dictadura argentina.

Abstract. This paper is aimed mainly at examining the performance of some of the leading public enterprises in the last Argentinian dictatorship (1976-1983) in terms of employment, wages, productivity, foreign debt, and investment, among others. The study is carried out using primary sources from public firms and statistical records, under the hypothesis that during those years the financial and technical-operative habilities of the firms deteriorated in a substantive way as a result of the implementation of a new capital accumulation regime, based on financial valuation, peripheral privatization, working class discipline and a change in the conception of entrepreneur state as a key actor in the development strategy.

Key words: entrepreneur State; public enterprises; Argentinian dictatorship.

Am. Lat. Hist. Econ., may.-ago., 2018, pp. 239-271 | DOI: 10.18232/alhe.866 
JEL: N460; N260.

Fecha de recepción: 9 de marzo de 2017. Fecha de aceptación: 17 de agosto de 2017.

Organismos colaboradores: Consejo Nacional de Investigaciones Científicas y Técnicas.

\section{INTRODUCCIÓN}

$\mathrm{E}$ 1 periodo histórico que transcurre en Argentina desde el golpe de Estado de 1976 hasta la restauración democrática a fines de 1983 estuvo signado por profundas transformaciones operadas en la estructura económica y social, así como por una redefinición del papel del Estado en la orientación de las políticas públicas. Ambos procesos exhibieron una estrecha vinculación, al mismo tiempo que trajeron aparejados algunos de los rasgos y tendencias más significativos de dicha etapa, tales como el proceso de concentración y centralización del capital, la configuración de un patrón de distribución regresiva del ingreso y el creciente deterioro de las capacidades del Estado y de sus niveles de autonomía relativa (Basualdo, 2010; Castellani, 2009; Schvarzer, 1986).

Son varios los trabajos que analizan la política económica desplegada por la última dictadura (entre ellos sobresalen Basualdo, 2010; Canitrot, 1983 y Schvarzer, 1981) y sus efectos sobre la reconfiguración del régimen social de acumulación (Torrado, 2010, pp. 21-22) -en especial, su impacto desindustrializador y la puesta en marcha de un modo de funcionamiento de la economía basado en la valorización financiera (Basualdo, 2010, pp. 449)-, la imposición de disciplina a la clase obrera y su funcionalidad respecto al más vasto proyecto político refundacional de la economía y la sociedad argentinas, que se sostuvo desde el denominado proceso de reorganización nacional.

Este proyecto no estuvo exento de tensiones y disputas que han salido a la luz en recientes investigaciones (entre ellas, Canelo, 2008; Novaro y Palermo, 2003; Pucciarelli, 2004; Quiroga, 2004 y Sidicaro, 2004). Ha habido controversias dentro del propio equipo económico entre liberales tradicionales y liberales tecnocráticos (Heredia, 2004) y en el seno del elenco gubernamental entre aquellas fracciones proclives a una mayor intervención estatal en el proceso económico (mayoritariamente ligadas a cierto sector de las fuerzas armadas con una tradición nacionalista, estatista e industrialista) y aquellas que preconizaban, desde una filosofía liberal y aperturista, el principio de subsidiariedad estatal (Canelo, 2008, 2016). Dicho principio propugnaba una creciente retirada del Estado de ciertas activida- 
des que se consideraban propias del sector privado. Esa retirada habría de quedar plasmada en la frase "achicar el Estado, para agrandar la Nación" que se convirtió en un lema comunicacional del gobierno en sus inicios. Puesto que el diagnóstico de la coalición golpista juzgaba excesiva la participación del Estado en la economía nacional, y la consideraba como una de las principales causas del desbordado proceso inflacionario que se vivía a comienzos de 1976, se estimaba pertinente una reducción del papel económico del Estado en términos tanto relativos como absolutos. Más allá de los diversos enfoques teórico-metodológicos, las investigaciones sobre las transformaciones económicas ocurridas durante la última dictadura argentina coinciden en señalar la relevancia que tuvo en la alianza gubernamental de entonces el tema de la participación del Estado en la economía y, en particular, el alcance y las características de sus funciones como productor de bienes y servicios estratégicos.

La preocupación sobre el papel del Estado y sus empresas se inscribe en una tradición más amplia de investigaciones sobre el Estado empresario en América Latina que puede sistematizarse en tres grandes líneas. En primer lugar, hay un conjunto de investigaciones sobre el Estado empresario en los procesos de desarrollo, ya sea desde una mirada general como es el caso Gillis (1980), o mediante un análisis comparado de la situación de las firmas públicas en América Latina vis à vis al desempeño de las empresas de propiedad estatal en Europa occidental, tal como lo ejemplifica el trabajo de Vernon (1980), o bien con un análisis de casos particulares como el de Belini y Rougier (2008) para el derrotero del Estado empresario argentino. También destacan en esta línea aquellos trabajos dedicados a precisar las transformaciones a partir de los años setenta y con mayor énfasis, desde la crisis de la deuda ya sea en la academia (Andrieu, 1975; Boneo, 1988; Marichal, 2011; Medellín, 1994; Saulniers, 1985, entre otros) o en los organismos internacionales, como el Banco Interamericano de Desarrollo (1983); el Centro Latinoamericano para el Análisis de la Democracia (1991), el Instituto Latinoamericano de Planificación Económica y Social (1981), y la Organización de las Naciones Unidas (1989), entre otros.

En segundo lugar, están aquellos estudios que abordan los procesos de estatización y/o privatización de empresas públicas desde comienzos del siglo XX hasta el presente. Aquí sobresalen los aportes de Costa y Miano (2013) que resaltan el desempeño de las empresas públicas durante los ciclos de expansión y retracción del sector público en la economía de Brasil entre 1930 y 2010; las investigaciones de Chávez y Cortés (2013) sobre la historia del Instituto Costarricense de Electricidad y la relevancia de este para entender el surgimiento de un peculiar estado de bienestar en Centroamérica; las aportaciones de Bertino, Rímoli, Torrelli y Vázquez (2011) acerca del estudio de los avatares de los niveles de inversión de las 
empresas públicas uruguayas durante el largo periodo de 1955 a 2010; las contribuciones de Costa, Pessali y Gonçalves (2013) sobre Petrobras desde su constitución y consolidación en el mercado interno brasileño hasta el despliegue de su reciente estrategia de internacionalización; el trabajo de Zuleta (2013) sobre las modalidades de vinculación productiva, comercial, técnica y política de Yacimientos Petrolíferos Fiscales Bolivianos con la empresa argentina Yacimientos Petrolíferos Fiscales (YPF) durante 19371945 , entre otros.

En tercer lugar, hay estudios dedicados a determinar y ponderar el tamaño óptimo y eficiente del Estado, y la relación entre Estado-mercado, entre los que sobresalen los trabajos acerca del caso chileno de Boeninger y Palma (1978) y Larroulet (1984), el de Casar y Peres (1988) para el caso del Estado empresario en México, el de Sojo (1984) sobre Costa Rica y el de Jeannot (1990) que muestra la interdependencia entre el Estado y el mercado en América Latina.

Ahora bien, aunque destacan valiosos aportes sobre el desempeño de algunas empresas públicas en particular y/o de algunas de las etapas por las que atravesó el Estado empresario en Argentina, ${ }^{1}$ aún son escasas las investigaciones que aborden con detenimiento el derrotero de las firmas estatales en su conjunto durante un periodo de profundos cambios en el modelo de acumulación y de fuertes cuestionamientos sobre el papel del Estado como productor de bienes y servicios. ${ }^{2}$ La historiografía de empresas y la economía política se centraron principalmente en el análisis de los beneficiados y perjudicados dentro del sector privado más que en el análisis agregado de las firmas estatales (Azpiazu, Basualdo y Khavisse, [1986] 2004; Castellani, 2009; Schorr, 2004). En este sentido, cंcómo afectaron los cambios en la orientación de las políticas aplicadas durante la última dictadura en el desempeño de las empresas públicas? Específicamente, ¿cómo incidieron en estas importantes firmas los procesos de privatización periférica (véase Schvarzer, 1986, pp. 275-276), ${ }^{3}$ la imposición de disciplina a

${ }^{1}$ En especial sobresalen los trabajos de Bleger y García (1988), Boneo (1980), Fernández (1976), Kaplan (1965), Regalsky y Rougier (2015), Rougier (2009), y Schvarzer (1979 y 1986).

${ }^{2}$ Con la excepción del sector hidrocarburífero, cuyo derrotero en clave histórica ha sido analizado profusamente en Barrera, Sabbatella y Serrani (2012), Bernal (2005), Kozulj y Bravo (1993), Solberg (1986), entre otros. Además, varios trabajos han hecho hincapié en las prácticas de corrupción y colusión público-privada en torno a la privatización periférica de YPF y a los contratos de explotación firmados por esta compañía estatal con empresas privadas durante la dictadura (entre otros, Castellani, 2009; Silenzi, 1978, y Verbitsky, 2006).

${ }^{3}$ La política de privatización periférica consistió, a grandes rasgos, en la transferencia, subcontratación y/o desviación de numerosas actividades y tareas que realizaba el Estado a través de sus diversas empresas y reparticiones públicas hacia un conjunto relativamente acotado de firmas privadas (mayoritariamente grandes grupos económicos locales). El procedimiento radicaba en el traspaso de algunas actividades al sector privado por medio de un contrato de cesión específico. Véase Schvarzer (1986, pp. 275-276). 
los trabajadores y el endeudamiento externo del Estado llevados adelante en esos años?

La pregunta adquiere relevancia en tanto estas firmas cumplían un papel estratégico en el proceso de desarrollo económico del país debido al tipo de bienes y servicios que producían, sus volúmenes de facturación, niveles de empleo y salarios. Entre 1975 y 1979, las empresas públicas argentinas explicaban, en promedio, 6.1\% del PBI (medido a costo de factores) y $14.4 \%$ de la inversión bruta interna fija, en consonancia con los indicadores internacionales disponibles para países desarrollados $(9.4 \mathrm{y}$ 13.4\%, respectivamente [Sindicatura General de Empresas Públicas, SIGEP, 1984a, p. 5]). Pero, además, hay que considerar la importancia política y simbólica que tenían estas empresas para amplios sectores, tanto civiles como militares, en términos de soberanía nacional e integración social. Tal como señala Guajardo (2013, p. 5), el estudio de las empresas públicas latinoamericanas se justifica por haber exhibido en el pasado una rica historia que ha atravesado diferentes modelos económicos o regímenes de acumulación de capital, "porque tras décadas de privatizaciones hay una débil memoria colectiva sobre estos organismos, predominando la versión neoliberal que justificó la venta del acervo público". Para analizar cómo afectaron los profundos cambios estructurales de fines de los años setenta a las empresas estatales, se identificarán las principales tendencias de desempeño de una muestra de firmas públicas del sector energético y de servicios, y se establecerán semejanzas y diferencias en función de los subperiodos y sectores de actividad en los que operaban. El análisis se centrará en la reconstrucción de un conjunto de indicadores seleccionados con base en la Sindicatura General de Empresas Públicas (en adelante SIGEP) para una muestra que incluye las siete empresas más importantes del sector energético y de servicios públicos (véase cuadro 1). Estos informes elaborados por la SigEP son las únicas fuentes disponibles en Argentina que presentan series temporales completas para el periodo de estudio y para todas las empresas públicas. El proceso de privatización de estas firmas durante la década de 1990-2000 implicó el desmantelamiento de sus archivos y bibliotecas y actualmente los balances no están disponibles para todos los años del periodo en cuestión. Tampoco en la Inspección General de Justicia se encuentran las series completas de los balances. Si bien los informes de la SigeP fueron elaborados por las propias autoridades del gobierno dictatorial, los datos que se pudieron cotejar con los balances existentes muestran correspondencia significativa. Sin desconocer sus limitaciones como fuente de información, se utilizan porque son las únicas disponibles que permiten reconstruir series temporales completas para todas las firmas durante el periodo de estudio. 
CUADRO 1. MUESTRA DE EMPRESAS PÚBLICAS SELECCIONADAS, INDICADORES RELEVANTES Y FUENTES CONSULTADAS

Firmas que integran
la muestra
Indicadores seleccionados
para cada firma

Fuentes utilizadas

\author{
Yacimientos Petrolíferos Fiscales (YPF) \\ Gas del Estado (GE) \\ Servicios Eléctricos del Gran Buenos Aires (SEGBA) \\ Agua y Energía Eléctrica (AYEE) \\ Empresa Nacional de Telecomunicaciones (ENTEL) \\ Ferrocarriles Argentinos (FA) \\ Obras Sanitarias de la Nación (OSN) \\ Facturación anual \\ Posición ranking empresario \\ Inversión real fija \\ Cantidad de trabajadores \\ Salario medio real \\ Productividad de la mano de obra \\ Precios y/o tarifas \\ Pasivos externos \\ Ranking empresarios, prensa especializada e informes \\ de la Sindicatura General de Empresas Públicas (SIGEP)
}

Fuente: elaboración propia.

Si bien el periodo de análisis es 1976-1983, en los cuadros 1, 2, 3, 4, 5, 6, 7, 8 y 9 y en las gráficas 1 y 2 se toma como punto de partida el año 1974 para tener una referencia más adecuada al ponderar los cambios acaecidos en el proceso respecto al derrotero de las variables. En el caso de los pasivos externos se tomó como base 1978, ya que no se dispone de la serie completa de la deuda externa de las firmas estatales para 1974-1983.

El trabajo se divide en tres apartados: el primero, destinado a precisar los principales cambios producidos en la orientación de la intervención estatal y en la organización de las actividades propias del Estado empresario; el segundo analiza el desempeño de las empresas públicas seleccionadas en términos de ventas, inversión, precios-tarifas y pasivos externos a fin de investigar el deterioro de las capacidades financieras de las firmas, y el tercero ahonda en las consecuencias que las políticas públicas tuvieron sobre los niveles de productividad, salarios y ocupación que marcaron el debilitamiento de las capacidades técnicooperativas de las empresas. Por último, se resumen los hallazgos más relevantes y se presentan algunas reflexiones que surgen del análisis de la evidencia empírica y la bibliografía académica. 


\section{MARCAS DISTINTIVAS DE LA GESTIÓN ECONÓMICA: DESREGULACIÓN Y APERTURA, REDISTRIBUCIÓN REGRESIVA DEL INGRESO Y EXPANSIÓN DEL ESTADO SUBSIDIARIO}

La política económica del ministro de Economía, José Alfredo Martínez de Hoz, se sostuvo en tres pilares: una reforma radical en el funcionamiento del sistema financiero, iniciada en 1977; una política abrupta y asimétrica de apertura comercial puesta en marcha hacia fines de 1978, y el ajuste de los precios domésticos, especialmente del salario, desde los momentos iniciales de su gestión ministerial en abril de 1976. Como consecuencia de la combinación de estas políticas, se produjo un viraje en el eje de valorización del capital que pasó del sector industrial al financiero, lo que destruyó una parte considerable del tejido manufacturero y provocó una reestructuración regresiva del sector secundario que, en su conjunto, pasó de 26.9\% del PBI en 1976 a menos de 24\% en 1983. Además, la política aperturista ocasionó una modificación sustancial en la estructura de precios y rentabilidades relativos en perjuicio de los bienes industriales transables (en especial los de consumo final) y generó una mayor concentración y centralización de capital en todos los sectores económicos (Castellani, 2009).

Por otra parte, y como corolario de la liberalización financiera, se incrementó como nunca antes el endeudamiento externo y la salida de capitales, en particular desde fines de 1978, lo que provocó una situación externa de alta vulnerabilidad y una constante transferencia de recursos hacia el exterior. Después, la casi completa estatización de los pasivos externos privados, realizada mediante diversos mecanismos diseñados desde el aparato estatal, significó una pesada carga para el sector público, que se tornó crónicamente deficitario (Basualdo, 2000, 2010; Damill y Frenkel, 1994).

Esta estrategia económica instaurada en un contexto en extremo represivo trajo aparejada una profunda redistribución de los ingresos en perjuicio de los asalariados, que perdieron 13\% de participación en el ingreso nacional en el primer año de la dictadura y más de 35 puntos de deterioro en los salarios medios como consecuencia del congelamiento de los salarios decretado por el gobierno en 1976 en pleno contexto inflacionario. Asimismo, la conjunción de las políticas mencionadas ocasionó cambios estructurales en el mercado laboral, una modificación de los tradicionales patrones de movilidad social y de los niveles de bienestar económico de la población en su conjunto. En definitiva, concentración y centralización del capital fueron las consecuencias más notorias de la gestión económica (Basualdo, 2010; Schvarzer, 1986).

Asimismo, las múltiples crisis que caracterizaron al periodo sustitutivo se redefinieron sustancialmente con el desarrollo de los mecanismos 
de valorización financiera generados hacia fines de los años setenta. En efecto, al cambiar el eje de valorización del capital, el problema dejó de ser el crecimiento errático del producto al compás de la crisis del balance comercial, como sucedía en la dinámica stop and go, y pasó a ser la pronunciada caída del producto industrial y de la inversión interna, combinada con déficits recurrentes y pronunciados en la cuenta corriente y capital del balance de pagos y en el sector público.

En este sentido, es necesario recordar que desde la dictadura el endeudamiento estatal alcanzó niveles inusitados que modificaron cualitativamente la crisis del sector externo y generaron un nuevo tipo de restricción (la deuda externa pública se multiplicó por seis entre 1976 y 1983). Este proceso deterioró sustancialmente la capacidad financiera y operativa del Estado que, al asumir como propia parte de la deuda privada, se vio obligado a conseguir y transferir cada vez más divisas hacia el exterior. A esta transferencia se sumaba el constante subsidio que realizaba el sector público a los sectores más concentrados del capital local, tales como la promoción industrial, la fijación de tarifas diferenciales, los reembolsos para ciertas exportaciones, entre otros mecanismos, que agudizaron aún más la brecha fiscal. El debilitamiento de la actuación estatal repercutió negativamente sobre los sectores sociales más perjudicados por los cambios en el modelo de acumulación. En efecto, la profunda redistribución regresiva de los ingresos y las dificultades para financiar políticas públicas universales modificaron los rasgos centrales de la estructura social que se tornó cada vez más fragmentada y excluyente. Al desaparecer la industria como el motor de crecimiento económico, se produjo un descenso en los niveles de empleo en los sectores primario y secundario en paralelo a un incremento en el sector terciario y en el de la construcción. Esto ayuda a explicar el desplazamiento de la ocupación hacia sectores de baja productividad relativa y el empobrecimiento general de vastos sectores de la población.

Sin embargo, y al mismo tiempo que la aplicación de las reformas liberales, la gestión económica estatal de la última dictadura impulsó notablemente el desarrollo del complejo económico estatal privado (Castellani, 2004; Schvarzer, 1979) mediante tres políticas complementarias: a) el aumento de la inversión pública en obras de infraestructura y la concesión de obras por el sistema de peaje que generaron numerosas demandas sobre las grandes empresas constructoras y las más importantes cementeras del país; $b$ la puesta en marcha de la política de privatización periférica, especialmente en el sector petrolero, que abrió nuevas posibilidades de realizar negocios rentables para algunas empresas privadas de capital nacional y en el telefónico; c) la fuerte promoción industrial para ciertos sectores considerados estratégicos para el complejo militar-industrial, tales como 
la siderurgia, el cemento, la petroquímica y el papel, proceso que benefició a numerosas empresas industriales de capital nacional y a unas pocas extranjeras. Dentro de este último factor debe incluirse, además, la puesta en marcha de emprendimientos mixtos (estatal-privado) fuertemente promovidos por el Estado, por ejemplo, el Polo Petroquímico Bahía Blanca.

Este incremento de la demanda estatal, sobre todo durante la gestión de Martínez de Hoz, generó importantes consecuencias en la actividad, la estructura del gasto público y el funcionamiento del aparato estatal y, especialmente, en el conjunto de empresas vinculadas al complejo. Respecto al nivel de actividad, Schvarzer (1981, 1986), Basualdo (2010) y Castellani (2009) coinciden en que el gasto y la inversión pública tuvieron un papel dinamizador de la economía mucho mayor que en periodos anteriores y que, a pesar de estar concentrada en algunas ramas específicas, esta demanda tuvo impactos significativos sobre muchas otras.

En relación con la composición del gasto, los criterios adoptados por el equipo económico permitieron conciliar los objetivos más ortodoxos, como la disminución del déficit fiscal, con otros más heterodoxos como la utilización de la inversión pública para incentivar la demanda global. Para lograr estos resultados, no sólo se aumentaron los recursos corrientes, sino que los asalariados del sector perdieron una parte considerable de sus ingresos reales, debido a que la disminución del déficit fiscal se originó por la fuerte caída de los gastos corrientes, en especial en los salarios del personal, lo que permitió el incremento del gasto no corriente. Asimismo, la multiplicidad de actividades generadas por el complejo exigió una transformación en las formas de control administrativo del aparato estatal, que ahora debía supervisar a los contratistas beneficiados por la privatización periférica y la concesión de obras públicas y, al mismo tiempo, hacer frente a los nuevos núcleos de interés que se conformaban en torno a la realización de las distintas actividades que se desarrollaban en ese ámbito específico.

En este sentido, se pone de manifiesto que el corte keynesiano de la acción estatal durante el periodo hace referencia exclusivamente al sentido contracíclico del gasto público sin que esto implique una distribución progresiva de los ingresos que favorezca el incremento del consumo de los sectores populares. La intervención estatal realizada fue sumamente regresiva, no sólo porque perjudicó a los asalariados, sino porque entre los capitalistas produjo un fuerte proceso de centralización del capital a favor de las empresas más grandes que se beneficiaron con las oportunidades de obtención de rentabilidades extraordinarias en sus negocios con el Estado (Castellani, 2009).

En efecto, las tasas de crecimiento del gasto público impactaron positivamente sobre una fracción de las empresas privadas gracias a las sig- 
nificativas transferencias de ingresos vía precios relativos; la creación de nuevos mercados centrados en requerimientos estatales (energía nuclear, equipos militares, entre otros); las modalidades de las licitaciones públicas de las empresas estatales (en las cuales se garantizaba el acceso exclusivo a muchos grupos económicos locales); la política de stock llevada adelante por las empresas y reparticiones estatales, así como la transferencia de actividades rentables realizadas por el Estado. Estos factores explican el desarrollo de una fracción de la burguesía integrada por

empresas grandes, con tendencia a formar conglomerados en torno a las actividades que brinda el sector público, con precios y mercados determinados en forma externa e independientes de sus costos [...] Empresas que nacen a partir de decisiones del sector público y que crecen en función del espacio dejado por este con un dinamismo que, objetivamente, no depende de ellas (Schvarzer, 1981, p. 29).

¿Qué sucedió con las empresas públicas mientras se producían estos profundos cambios en la estructura y dinámica socioeconómica del país? ¿Cómo incidieron esas políticas que tanto beneficiaron a las empresas privadas en el desempeño de las empresas estatales? En términos agregados, las estadísticas públicas disponibles señalan un retroceso de la participación de estas firmas en el empleo formal total (pasaron de 5.7 a 3.9\%) y en la inversión bruta interna fija (de 17.5 a 11.7\%) para el periodo 1976-1981, acompañado de un incremento en la participación del PBI global medido a costo de factores de 6.1 a 6.9\% entre 1976 y 1980 (SIgEP, 1984a, pp. 17-20).

En los dos apartados siguientes se abordarán estos temas para una muestra de empresas públicas y del comportamiento de algunas variables clave que permiten inferir la pérdida de capacidades financieras y técnicooperativas de las firmas, además del deterioro relativo de las capacidades del Estado empresario argentino durante esos años.

\section{DETERIORO DE LAS CAPACIDADES FINANCIERAS:}

ENDEUDAMIENTO PRONUNCIADO Y DESACOPLADO

DE LA INVERSIÓN REAL Y DE LA EVOLUCIÓN DE PRECIOS Y TARIFAS

Hacia mediados de la década de 1970, las empresas públicas ocupaban un lugar destacado en el podio de las grandes firmas del país por los volúmenes de ventas y la participación en la generación del PBI, que en 1976 alcanzaba $6.1 \%$. La mayor empresa de Argentina era la petrolera estatal YPF, que ocupó el primer puesto en el ranking de ventas durante varias décadas. Gas del Estado, ENTEL, SEgbA y AYEE, por su parte, se ubicaban 
entre los primeros diez lugares en el listado de las 200 firmas de mayor nivel de facturación en 1974 .

Desde 1973 estas firmas estaban coordinadas por la Corporación de Empresas Nacionales, dependiente del Ministerio de Economía, ya que las autoridades de entonces consideraban que "el desarrollo económico y social del país requiere como condición necesaria que este amplio grupo de empresas brinde servicios y productos en cantidad crecientes, de calidad cada vez mayor y a costos cada vez menores al tiempo que sus acciones coadyuven al mejor desarrollo del resto de la actividad económica a la cual se ligan" (Ley 20.558/73, p. 8).

La Corporación de Empresas Nacionales fue liquidada en 1978 por la última dictadura (Ley 21.800/78) y reemplazada por la SigeP (Ley 21.801/78); este organismo mantuvo su dependencia del Ministerio de Economía y su director era el propio ministro. El cambio implicó abandonar los objetivos de desarrollo previstos en la ley de 1973 y la coordinación estratégica para lograrlos, ya que con el nuevo marco normativo las principales funciones de la SiGEP eran el control y el seguimiento del desempeño de las firmas, y la información y asesoramiento al Ministerio (artículos 4 y 5, Ley 21.801/78).

El análisis de la evolución de las ventas de las empresas públicas seleccionadas, que figuraban entre las más grandes del país según su facturación anual (véase cuadro 2), indica, como denominador común, la existencia de un comportamiento errático de sus ingresos, pese a los diferentes sectores de actividad en el cual se desempeñaban. En ese sentido, sólo tres de las siete firmas analizadas exhibieron como resultado global, más allá de las fuertes variaciones interanuales, un crecimiento de sus ingresos por ventas a lo largo del periodo 1974-1983 (sobresale el caso de Gas del Estado, cuyas ventas aumentaron casi $72 \%$ ); el resto de las empresas consideradas mostraron un desempeño desfavorable; tales son los casos de Ferrocarriles Argentinos, AYEE, ENTEL y Obras Sanitarias de la Nación (OSN), pues experimentaron fuertes descensos en sus ingresos.

Ello se explica por la puesta en marcha de una política económica que declaraba, con las contradicciones ya señaladas, la subsidiariedad del Estado nacional en la economía y que prescindía de su capacidad de intervención y planificación estratégica. Dicha política se aplicó a las empresas públicas, y más allá de las particularidades socioeconómicas y tecnológicas de las diferentes firmas, derivó en la privatización periférica, la racionalización de sus actividades y, en algunos casos, la transferencia de sus incumbencias a las jurisdicciones provinciales.

También se constata un comportamiento errático en la evolución de los precios y/o tarifas tendentes a la baja (excepto en los casos de YPF y Gas del Estado) y profundas divergencias en la evolución de la inversión real 


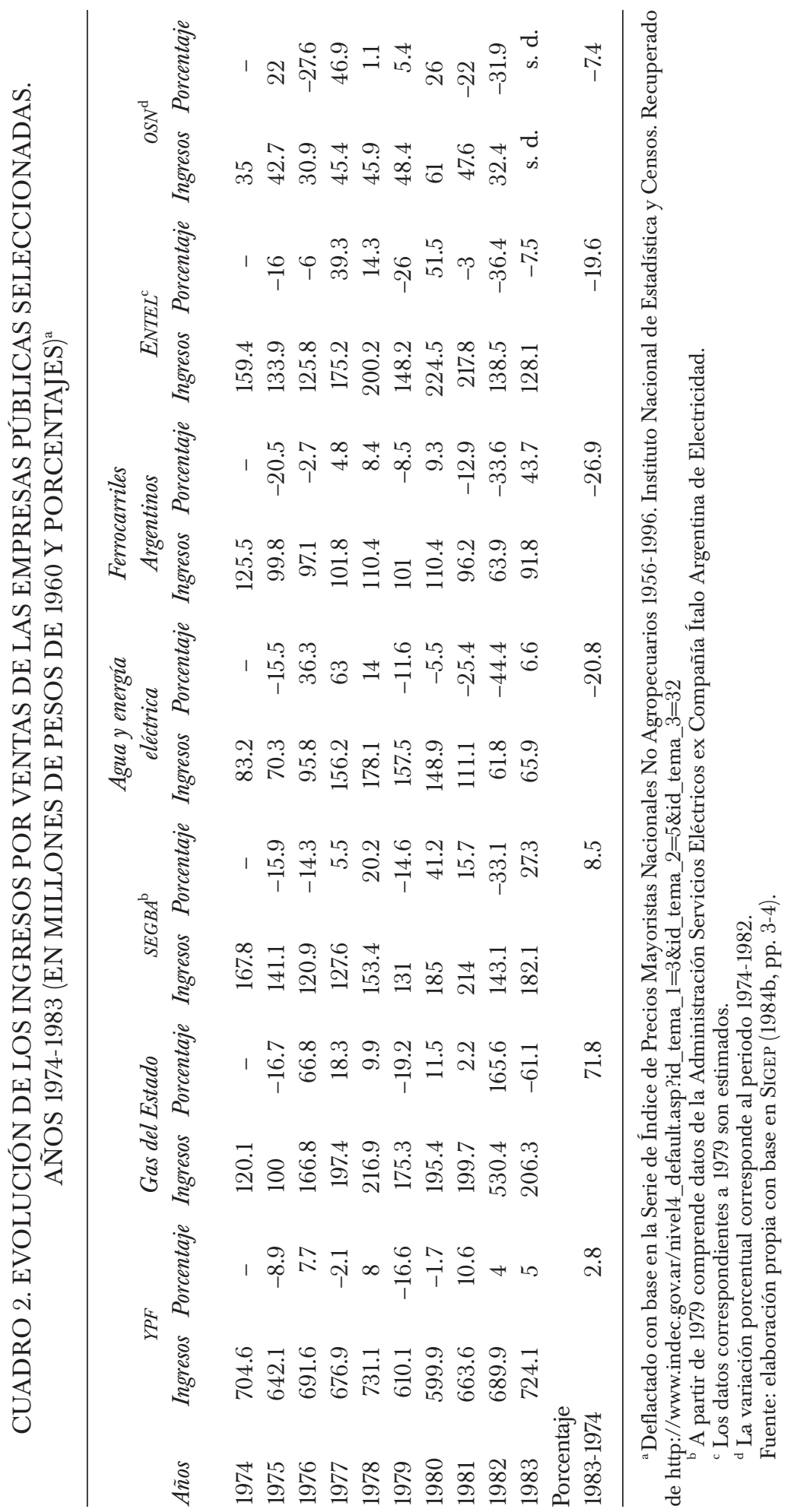


fija de las empresas, aunque con tendencia generalizada a la baja de entre uno y 80 puntos porcentuales (excepto en el caso de ENTEL, cuya tasa de inversión se incrementa hasta casi duplicarse a lo largo del periodo). En efecto, YPF y Gas del Estado presentan fuertes incrementos de la inversión en la primera etapa (1976-1980 y 1976-1978, respectivamente) y marcados descensos a partir de 1979 y 1980.

Por su parte, SEGBA, OSN y AYEE muestran una tendencia pronunciada a la caída de la inversión a lo largo de todo el periodo, y Ferrocarriles Argentinos, una tendencia errática, aunque con resultado negativo (véanse cuadros 3 y 4 ).

En un principio se argumentaría que el comportamiento errático de estas variables obedece a los avatares del ciclo económico, pero existen algunos indicios de que no necesariamente se haya producido tal correspondencia. En el caso de YPF, el sendero seguido por la inversión estuvo sujeto a importantes fluctuaciones que no presentan un correlato con el nivel de actividad general de la economía argentina. Así, mientras que en 1978 el nivel de actividad experimentó un fuerte descenso en relación con 1977 (año de crecimiento económico), la inversión de la petrolera estatal, por su parte, mostró un alza de $23.4 \%$ respecto al año anterior. Por otro lado, más allá de las oscilaciones, es evidente el creciente proceso de desinversión en las empresas energéticas que no se explica por la caída del nivel de actividad. Tampoco puede explicarse la evolución de la inversión vis a vis al ciclo económico en el caso de Ferrocarriles Argentinos cuyos niveles de inversión disminuyeron 26\% en 1977 (año de expansión del PBI) respecto a 1976, o en el caso de OSN, donde la contracción de la inversión fue más acentuada y sostenida a lo largo de todo el periodo en cuestión. En sentido contrario, se observa que ENTEL fue una de las pocas empresas públicas que lograron niveles de inversión superiores a los de 1974 con momentos de pronunciadas alzas y bajas en este indicador. Por ejemplo, la inversión de la empresa estatal de telecomunicaciones de 1981 fue mayor a 133\% de la del año base (1981 fue un año de fuerte caída del PBI), mientras que, en 1982, se evidenció un brusco descenso interanual de 32.6\%. Se observa cierta correspondencia con el descenso en el nivel de actividad general, ya que 1982 fue un año de retracción del producto bruto, aunque esta merma de la economía argentina fue, en términos relativos, menos pronunciada que la caída en el nivel de inversión de ENTEL (véase cuadro 5).

Lo mismo se puede señalar respecto a precios y tarifas, que tienen fuertes variaciones interanuales en todas las empresas públicas. Excepto Gas del Estado, el resto de las empresas energéticas presentan niveles de precios y tarifas relativos más bajos en 1983 que en 1974.

A la par del menoscabo en sus ingresos, las principales firmas del sector energético estuvieron expuestas a un creciente proceso de endeudamiento 


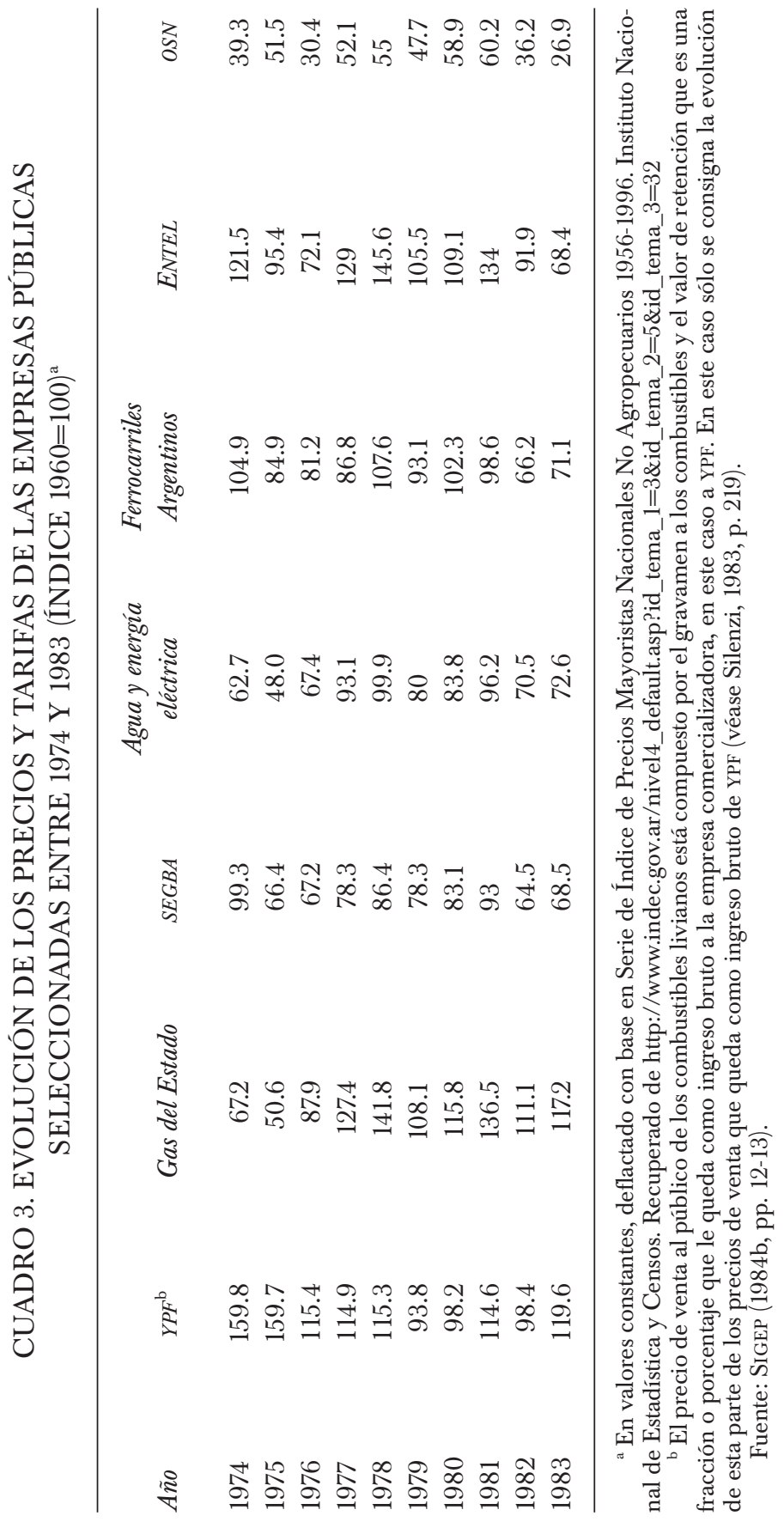




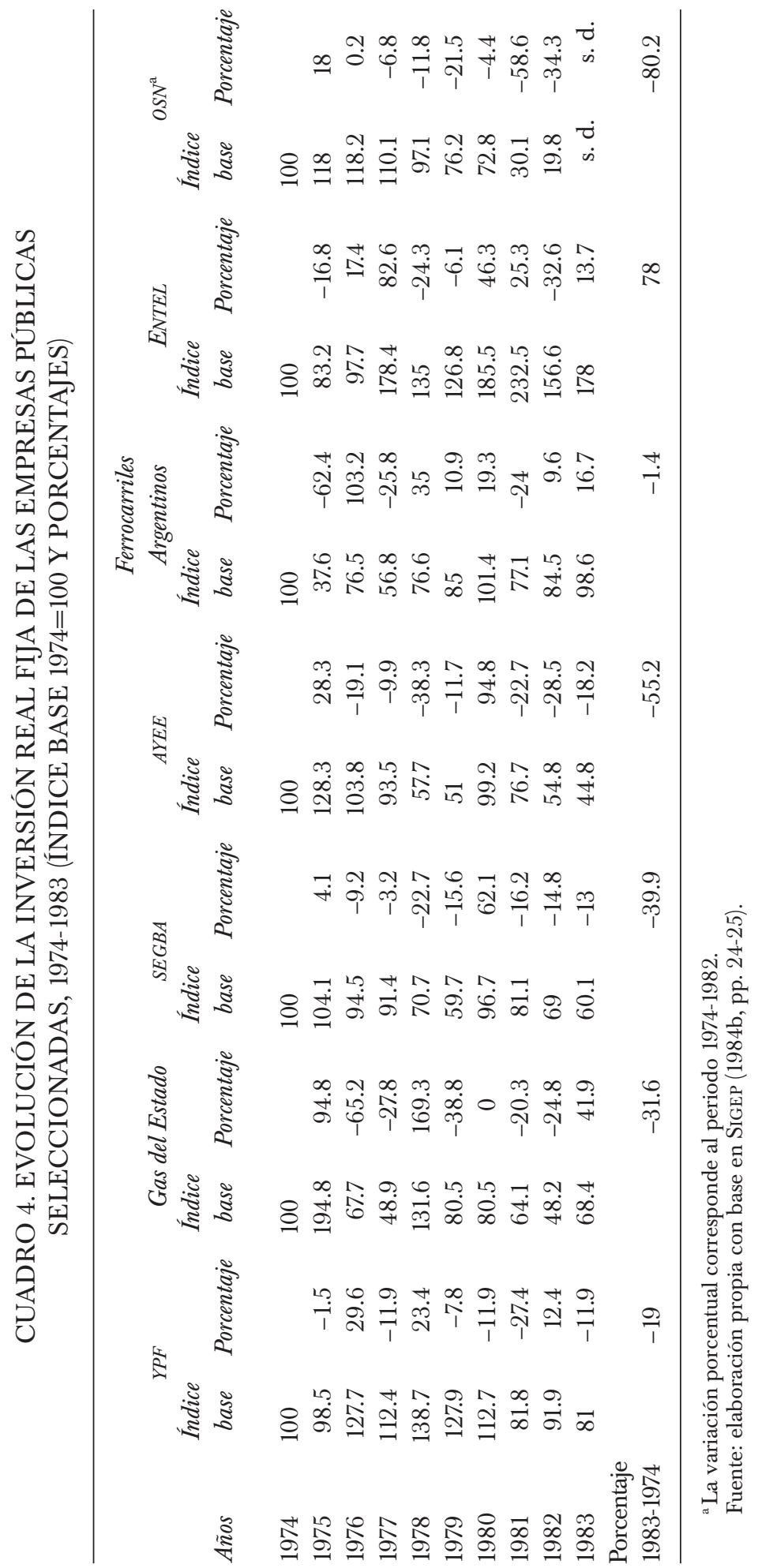


CUADRO 5. EVOLUCIÓN DEL PBI GLOBAL DE LA ECONOMÍA ARGENTINA. AÑOS 1974-1983 (EN MILES DE PESOS ARGENTINOS DE 1970 A PRECIOS DE MERCADO, ÍNDICE BASE 1974=100 Y PORCENTAJES)

\begin{tabular}{|c|c|c|c|}
\hline Años & $P B I$ & $\begin{array}{l}\text { Indice base } \\
1974=100\end{array}$ & $\begin{array}{c}\text { Variable interanual } \\
\text { (porcentaje) }\end{array}$ \\
\hline 1974 & 10144.3 & 100 & \\
\hline 1975 & 10105.3 & 99.6 & -0.4 \\
\hline 1976 & 10058.4 & 99.2 & -0.5 \\
\hline 1977 & 10699.5 & 105.5 & 6.4 \\
\hline 1978 & 10388.8 & 102.4 & -2.9 \\
\hline 1979 & 11032.2 & 108.8 & 6.2 \\
\hline 1980 & 11114.2 & 109.6 & 0.7 \\
\hline 1981 & 10421.2 & 102.7 & -6.2 \\
\hline 1982 & 9868.6 & 97.3 & -5.3 \\
\hline 1983 & 10144.4 & 100 & 2.8 \\
\hline \multicolumn{4}{|l|}{ Porcentaje } \\
\hline 1983-1974 & & & 0 \\
\hline
\end{tabular}

Fuente: elaboración propia con base en Fundación de Investigaciones para el Desarrollo (1984, p. 3).

en moneda extranjera, como parte de la estrategia del equipo económico de la dictadura de proveer las divisas necesarias para que los agentes privados que participaban de la especulación financiera tuvieran los recursos imprescindibles para girar sus ganancias al exterior (ciclo endeudamiento público-fuga de capitales propio de la valorización financiera del capital).

Esa lógica especulativa, rentística y cortoplacista, fue posible, entre otras cosas, por el excesivo endeudamiento de la petrolera estatal YPF (la mayor empresa del país), que pasó en 1978 de una deuda de 1322 millones a 4451 millones de dólares en 1983, lo cual supuso un aumento de 237\%. Durante el trienio 1979-1981 se registró la mayoría de los préstamos en el mercado financiero internacional (véase cuadro 6); este endeudamiento no guarda correlato con la evolución de la tasa de variación de la inversión de la petrolera estatal, que cayó sistemáticamente en ese mismo periodo.

De manera análoga, las otras firmas analizadas experimentaron un alto incremento en los montos de sus pasivos externos que, en la mayoría de los casos, no concordaba con mayores requerimientos de inversión. Entre 1978 y 1983 el aumento de la deuda externa de Gas del Estado, SEGBA, AYEE, Ferrocarriles Argentinos y ENTEL fue, respectivamente, de 450, 77, 


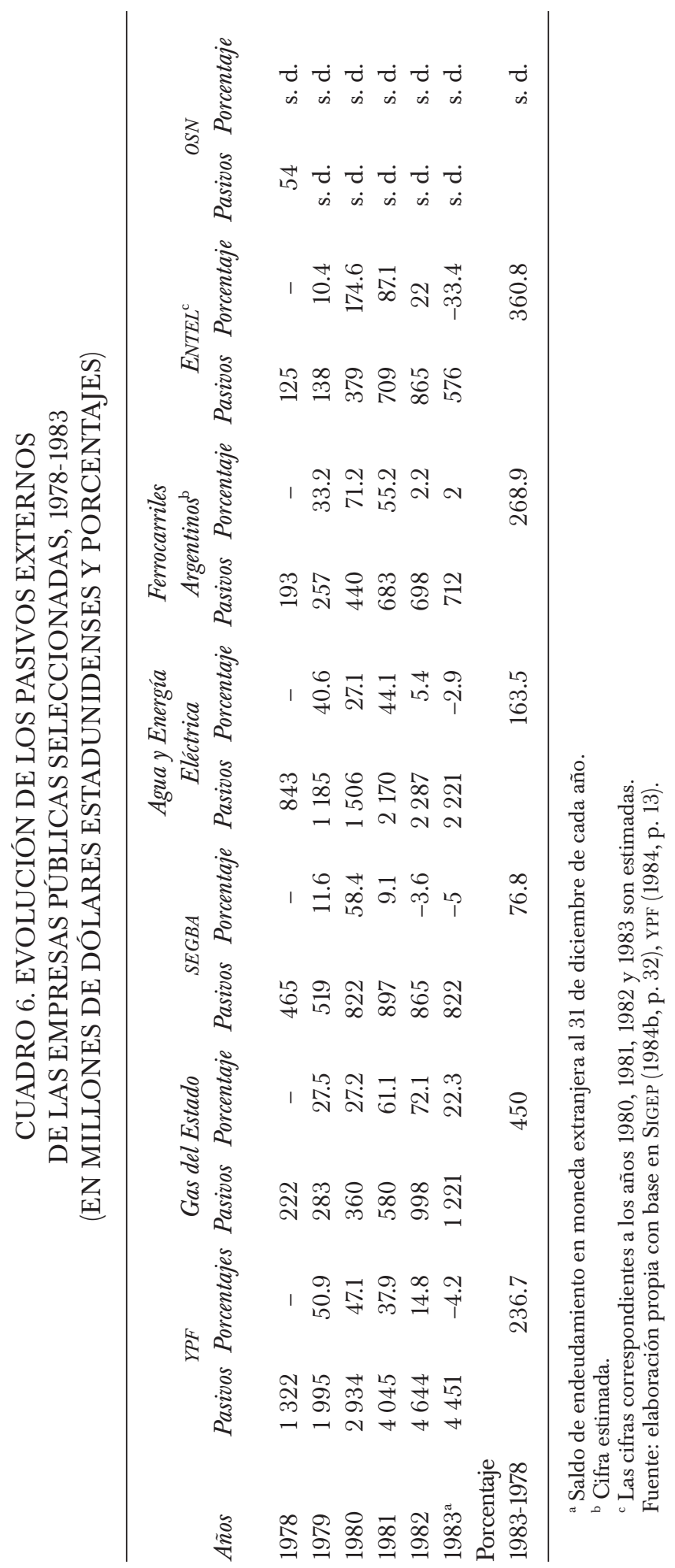


164, 269 y $361 \%$. Asimismo, las firmas del sector energético representaban cerca de $80 \%$ del volumen global de deuda de las empresas públicas bajo control de la SigEP, es decir, 9297 millones de dólares sobre un total de 11701 millones (véase cuadro 7). ${ }^{4}$

El revés de esa trama de endeudamiento externo de las empresas públicas fue el endeudamiento externo de los grandes grupos económicos locales y extranjeros, la fuga de capitales que protagonizaron y la estatización de sus pasivos externos. Entre los más importantes contratadores de crédito en el mercado internacional se encontraban, entre otras, las principales firmas que participaron en la privatización periférica de YPF y Gas del Estado. Entre ellas, destacan el consorcio Cogasco, S. A. (el segundo mayor grupo deudor externo privado), que fue el adjudicatario de la construcción del Gasoducto Centro Oeste; los grupos nacionales contratistas de YPF: Pérez Companc, Bridas y Astra, quienes a fines de 1983 ocupaban, en el ranking de los 50 grupos económicos con mayor deuda externa contraída, los puestos cuarto, sexto y decimotercero, respectivamente, y el conglomerado extranjero Techint (también contratista de YPF), el cual se situaba en el noveno puesto del mencionado ranking (véase Basualdo, 1987, p. 178).

La marcada divergencia entre el sendero de las variables inversión, precios y/o tarifas y deuda externa, da cuenta de una política deliberada de endeudamiento externo de todas las empresas públicas que no muestra correlación con un aumento de la inversión real fija. Los abultados pasivos externos impactaron negativamente en el desempeño de dichas firmas en los años posteriores y debilitaron sus posiciones financieras de un modo acuciante, y constituyen una de las causas principales del deterioro sufrido en la calidad de la producción de bienes y servicios públicos.

Sin embargo, este deterioro de las capacidades financieras de las empresas públicas de la muestra analizada se complementa con un marcado retroceso en sus capacidades técnicooperativas, debido a la aplicación de políticas muy severas de racionamiento de la plantilla de personal, descentralización de servicios que fueron transferidos sin recursos financieros acordes a las administraciones provinciales y la contratación de intermediarios en algunas actividades clave (reparaciones, mantenimiento, explotación de áreas exploradas, por ejemplo) en favor de empresas privadas con mecanismos de privatización periférica.

\footnotetext{
${ }^{4}$ YPF alcanzaba 38\% de la deuda total de las empresas de la SIGEP y cerca de $10 \%$ del endeudamiento externo total de Argentina (YPF, 1984, p. 7).
} 


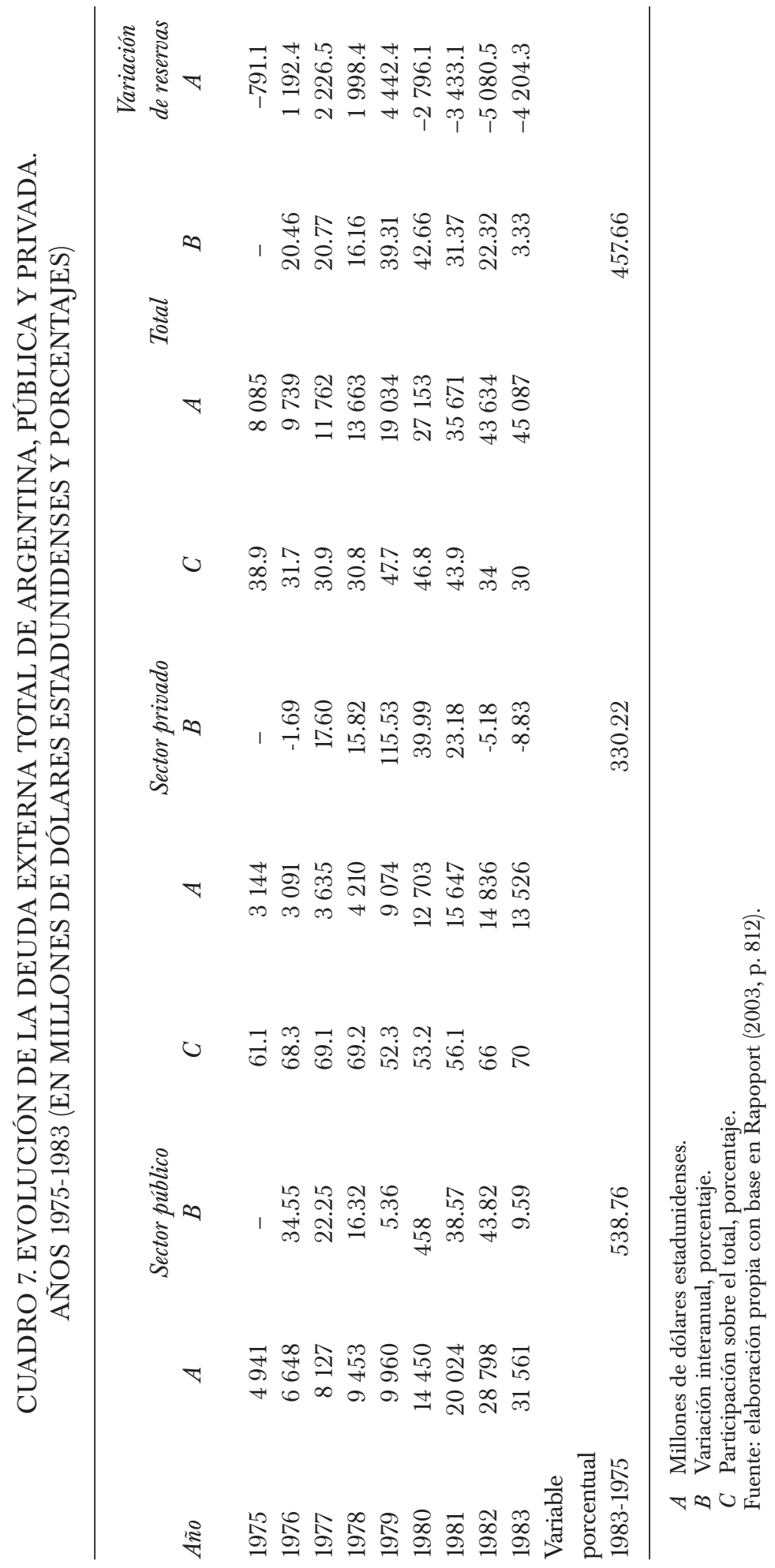




\section{EL DETERIORO DE LAS CAPACIDADES TÉCNICAS Y OPERATIVAS: RACIONALIZACIÓN DE LA DOTACIÓN DE TRABAJADORES, REDUCCIÓN DE LOS SALARIOS Y AUMENTO DE LA PRODUCTIVIDAD LABORAL}

Uno de los propósitos centrales del gobierno militar fue la desarticulación, desmovilización e imposición de disciplina a la clase obrera. Si bien la literatura especializada ha indagado los efectos sobre los trabajadores de la industria manufacturera, en especial los del sector privado, se han estudiado relativamente poco las características y las consecuencias que generaron estas políticas en las empresas estatales. Por eso, y para investigar la formación de capacidades técnicooperativas, se revela la evolución de sus dotaciones de empleados, la trayectoria seguida por las remuneraciones y el desempeño en términos de productividad.

Desde el inicio de la gestión de Martínez de Hoz, en 1976, todas las empresas públicas fueron expuestas a un proceso de racionalización de sus planteles laborales, en consonancia con el principio de subsidiariedad estatal y la política de privatización periférica (véase cuadro 8). En general, las reducciones más significativas se realizaron en AYEE y OSN con $50 \%$ de disminución de personal entre 1976 y 1983. En cuanto a los salarios reales promedio, se registran caídas pronunciadas a lo largo de 1974-1983, en algunos casos cercanos a 25\% (SEGBA y AYEE). Ambos fenómenos implicaron un incremento de la productividad del trabajo en todas las firmas (que oscilan entre 33 y 162 puntos) durante el periodo en cuestión, especialmente elevada en los casos de AYEE, OSN, SEGBA e YPF.

En efecto, si se analiza la evolución de la cantidad de empleados, se comprueba, aunque con matices, una reducción en el número de agentes ocupados en todas las firmas. En el caso de las energéticas, las caídas más pronunciadas se observan en YPF, que fue sometida a un proceso de privatización periférica desde 1977, y que implicó la contratación de intermediarios para las actividades de explotación petrolera en favor de empresas privadas. En cuanto a las empresas eléctricas se advierte que también atravesaron por la racionalización en sus niveles de ocupación, en especial en AYEE. En el caso de Ferrocarriles Argentinos también se produjo el recorte en la cantidad de trabajadores de 42\%, al pasar de 154949 a 95804 empleados entre 1976 y 1981. No obstante, OSN es uno de los ejemplos más elocuentes de la drástica reestructuración experimentada por una empresa estatal durante la dictadura, ya que la contracción en su plantel laboral fue cercana a 65\%, de 26000 a 9400 para 1974-1983. Gran parte de esa disminución se explica por la transferencia de la prestación del servicio de agua potable y saneamiento desde el Estado nacional hacia las provincias y la absorción por parte de estas de una proporción del personal desafectado 


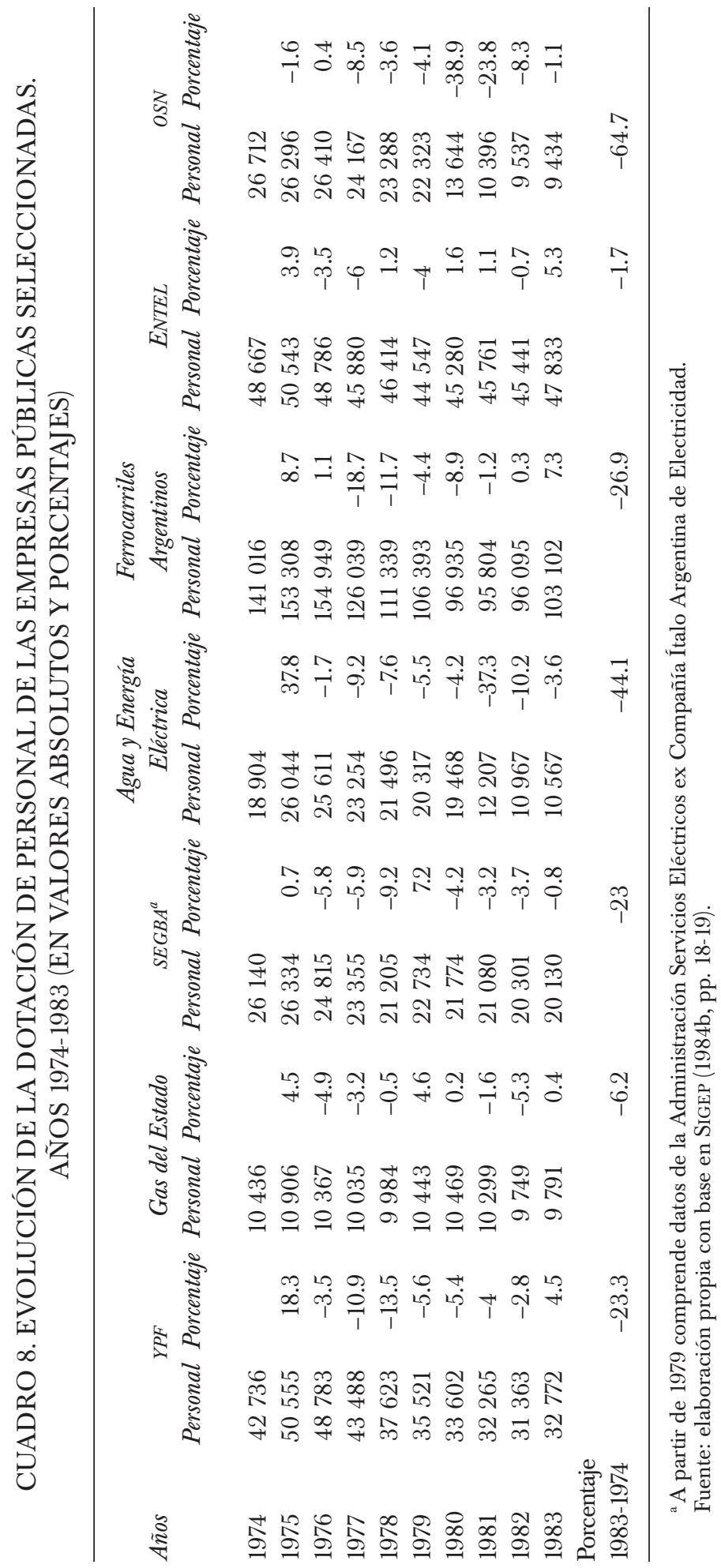


(en el marco del principio de subsidiariedad estatal y la descentralización de servicios básicos).

Por su parte, el caso de la empresa ENTEL es, en términos relativos, donde la disminución de ocupados fue menor. Si se toma como punto de comparación el periodo 1976-1983, se pasó de 48786 a 47833 empleados. Sin embargo, el análisis interanual revela un reemplazo del personal, ya que entre 1976 y 1979 se retiraron 600 trabajadores que luego se reemplazaron por otros 500, aproximadamente.

En cuanto a la evolución salarial, las empresas energéticas también mostraron un comportamiento a la baja, en consonancia con lo acaecido en el resto de la economía argentina (véase cuadro 9). Se pueden discernir, pese a las abruptas variaciones interanuales, dos momentos diferenciados. El primero de ellos comienza en 1975 con el llamado Rodrigazo ${ }^{5}$ y se caracteriza por una tendencia descendente en los salarios de las empresas energéticas, al igual que el descenso seguido por las remuneraciones del sector manufacturero, y abarca, según los casos, hasta 1977-1978 aproximadamente. La aplicación durante los primeros años del proceso de una severa reducción de las remuneraciones de los trabajadores, en especial de los empleados públicos, constituye un verdadero hito en la historia económica argentina, ya que representa una drástica redistribución regresiva del ingreso y marca un límite histórico más bajo en los niveles salariales.

A partir de 1979 se registra una recuperación de los salarios reales de las cuatro empresas energéticas consideradas, que se prolonga hasta alrededor de 1980. A la postre, vuelven a descender las remuneraciones reales de los trabajadores de dichas firmas hasta 1982 inclusive; más adelante, en el último año de la dictadura, se observa una leve recuperación del poder de compra. No obstante, en los casos de YPF y Gas del Estado los salarios de 1983 eran de 1 y 10\%, respectivamente, por debajo de los niveles de 1974; mientras que para las firmas del subsector eléctrico (SEGBA y AYEE), las remuneraciones eran de 25 y $27 \%$, respectivamente, por debajo de las cifras de 1974 .

En el mismo sentido, si se analiza, más allá de las fuertes variaciones interanuales, la evolución de más largo aliento de los salarios reales de Ferrocarriles Argentinos, se constata una pérdida de 5\% del poder adqui-

\footnotetext{
${ }^{5}$ Alude a la política de ajuste ortodoxo encarada por el ministro de Economía, Celestino Rodrigo, durante la presidencia de María Estela Martínez de Perón en junio de 1975. Básicamente, esta consistió en una abrupta devaluación del tipo de cambio (se pasó de una tasa cambiaria de quince pesos por dólar a otra de 30 por la misma cantidad de la divisa estadunidense), seguida de un notable incremento en los precios y tarifas públicos (en el caso de la gasolina se llegó a un aumento de 200\%). De manera simultánea, se les ofrecía a los sindicatos un incremento salarial inferior a 40\%. Esto implicó un salto exponencial en los niveles de inflación (véase Di Tella, 1983, p. 211).
} 


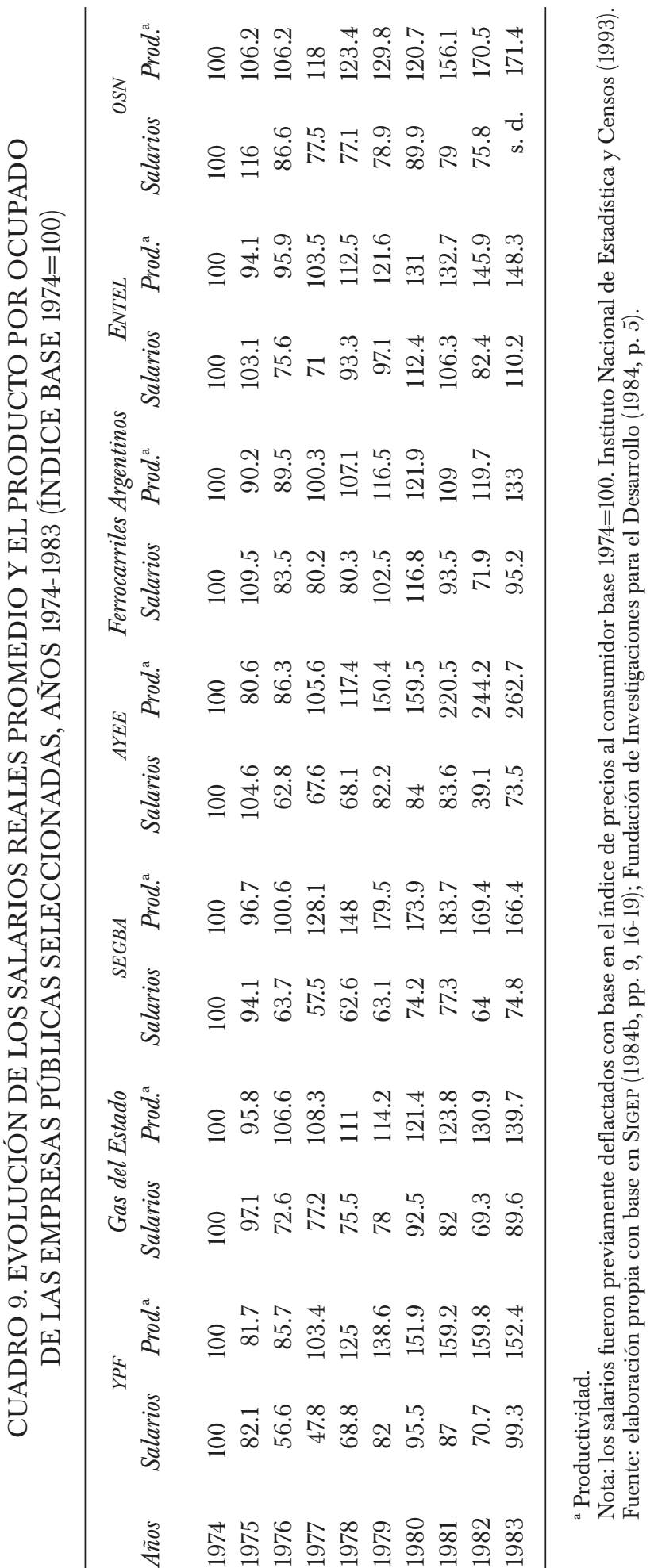


sitivo entre 1974 y 1983. Mientras, en el caso de OSN, si se toma como punto de comparación 1974-1982, la merma es de 24\%. Sin embargo, el derrotero seguido por las remuneraciones reales es similar al exhibido por los salarios de las empresas energéticas, es decir que se corrobora a partir de 1975 hasta 1977-1978, aproximadamente, una caída de la capacidad de compra de los salarios de los trabajadores de Ferrocarriles Argentinos y OSN, para luego percibirse una recuperación del poder adquisitivo hacia 1980 y, al final, volver a experimentar un menoscabo en los últimos años de la dictadura.

La única excepción en materia salarial la constituye el caso de ENTEL, en la que, al comparar los años 1974-1983, se observa un incremento de las remuneraciones promedio de $10 \%$. Sin embargo, el rumbo seguido por los salarios de los trabajadores de dicha empresa fue relativamente similar, en términos de las bruscas variaciones interanuales, al de las otras firmas públicas analizadas, ya que los salarios sufrieron una fuerte caída en el bienio 1975-1976; luego, hubo una tendencia al alza hasta 1980 inclusive y en 1981-1982 y un descenso de manera significativa, muy por debajo de los niveles de 1974 (los salarios de 1982 eran 18\% más bajos que los de 1974). Apenas en el último año de la serie (1983), los salarios experimentaron una importante recuperación que les permitió superar 10\% de los registros del año base (1974).

En lo que atañe a la evolución de la productividad de las empresas energéticas, se puede comprobar el significativo incremento del producto por ocupado (véase cuadro 9). Así, para el caso de YPF la productividad de 1983 estaba 52\% por encima del registro de 1974 (mientras que en 1982 se registró el mayor nivel de la serie, y la productividad de ese año fue casi $60 \%$ más elevada que la de 1974). De todos modos, los mayores incrementos interanuales tuvieron lugar en los primeros años de la dictadura, sobre todo entre 1977 y 1978, cuando los aumentos del producto por ocupado fueron, respectivamente, de 20.6 y $20.9 \%$ respecto al año inmediatamente anterior. En el caso de Gas del Estado, la productividad de 1983 era casi 40\% más alta que la de 1974, es decir registró una tendencia ascendente a lo largo de todo el periodo del estudio.

En cuanto a las firmas del subsector eléctrico, también se observa el acrecentamiento de los niveles de productividad. En ese sentido, SEGBA experimentó un alza del producto por ocupado de 66\% en 1983 con respecto a las cifras de 1974. A su vez, el importante incremento del producto por ocupado, que en el caso de la empresa AYEE es 163\% más elevada en 1983 en relación con 1974, se produjo -en lo esencial- no sólo por un mayor nivel de producción, sino por la conjunción entre un incremento en el producto y la fortísima racionalización del plantel laboral de la firma energética. Eso indica que, más allá de ese mayor volumen de producción, 
los trabajadores se vieron sometidos, muy probablemente, a niveles más elevados en la explotación de su fuerza de trabajo. ${ }^{6}$ Por otra parte, en el caso de Ferrocarriles Argentinos, ENTEL y OSN, también se corrobora un sostenido aumento de la productividad que, para las tres firmas consideradas, en 1983 era respectivamente superior en 33, 48 y 71\% a los registros del año 1974.

Ahora bien, si la perspectiva de análisis se sitúa en torno a la relación productividad y salarios, se evidencia un incremento del excedente económico en las empresas públicas analizadas, especialmente pronunciado en los casos de SEGBA y AYEE (véanse gráficas 1 y 2).

Este hecho encuentra una explicación plausible en Boneo (1988) acerca del cambio de tendencia en el desempeño de las empresas estatales bajo gestiones liberales-privatistas. En efecto, durante dichas gestiones el autor constató que el aumento del valor agregado generado por las firmas públicas se debía, por un lado, a los cambios operados en la estructura de precios y rentabilidades relativas (devaluación del tipo de cambio y mediante actualización tarifaria) y, por otro, a la sensible disminución de la participación de las retribuciones de los trabajadores sobre ese mismo valor agregado a causa de las reducciones de personal y de los salarios reales. Este último dato es un factor que potenciaba el aumento del superávit bruto de explotación, es decir, de los excedentes a disposición de las empresas públicas. Ello no quiere decir que dichos excedentes hayan sido necesaria y efectivamente apropiados por las empresas públicas. Dados los cambios permanentes en la estructura de precios y rentabilidades relativas de la economía argentina durante el periodo en estudio y los manejos discrecionales en la fijación de las tarifas de las firmas estatales, es muy probable que se haya producido una importante transferencia de recursos desde estas empresas hacia los consumidores y o usuarios privados de los servicios públicos. Además, resulta plausible conjeturar que los principales beneficiarios de dicha transferencia hayan sido las grandes empresas privadas industriales y comerciales vía el pago de tarifas más bajas que las abonadas por los clientes residenciales.

\footnotetext{
${ }^{6}$ En el caso puntual de AYEE, gran parte de la racionalización de su plantel laboral estuvo asociada no sólo con la política de privatización periférica, sino también con la "provincialización" de ciertos servicios esenciales que prestaban algunas importantes empresas públicas. Esto era la transferencia sin cargo que AYEE debió efectuar hacia las provincias de los servicios de subtransmisión, distribución y generación aislada dentro de las respectivas jurisdicciones donde la empresa estatal operaba. Dicha transferencia fue posibilitada por la Resolución Conjunta núm. 9 y 1.332 de los ministerios del Interior y Economía, respectivamente, fechada el 3 de diciembre de 1979 y ratificada después por el decreto del poder ejecutivo nacional núm. 258 del 3 de enero de 1980 (Fundación de Investigaciones Económicas Latinoamericanas, 1987).
} 


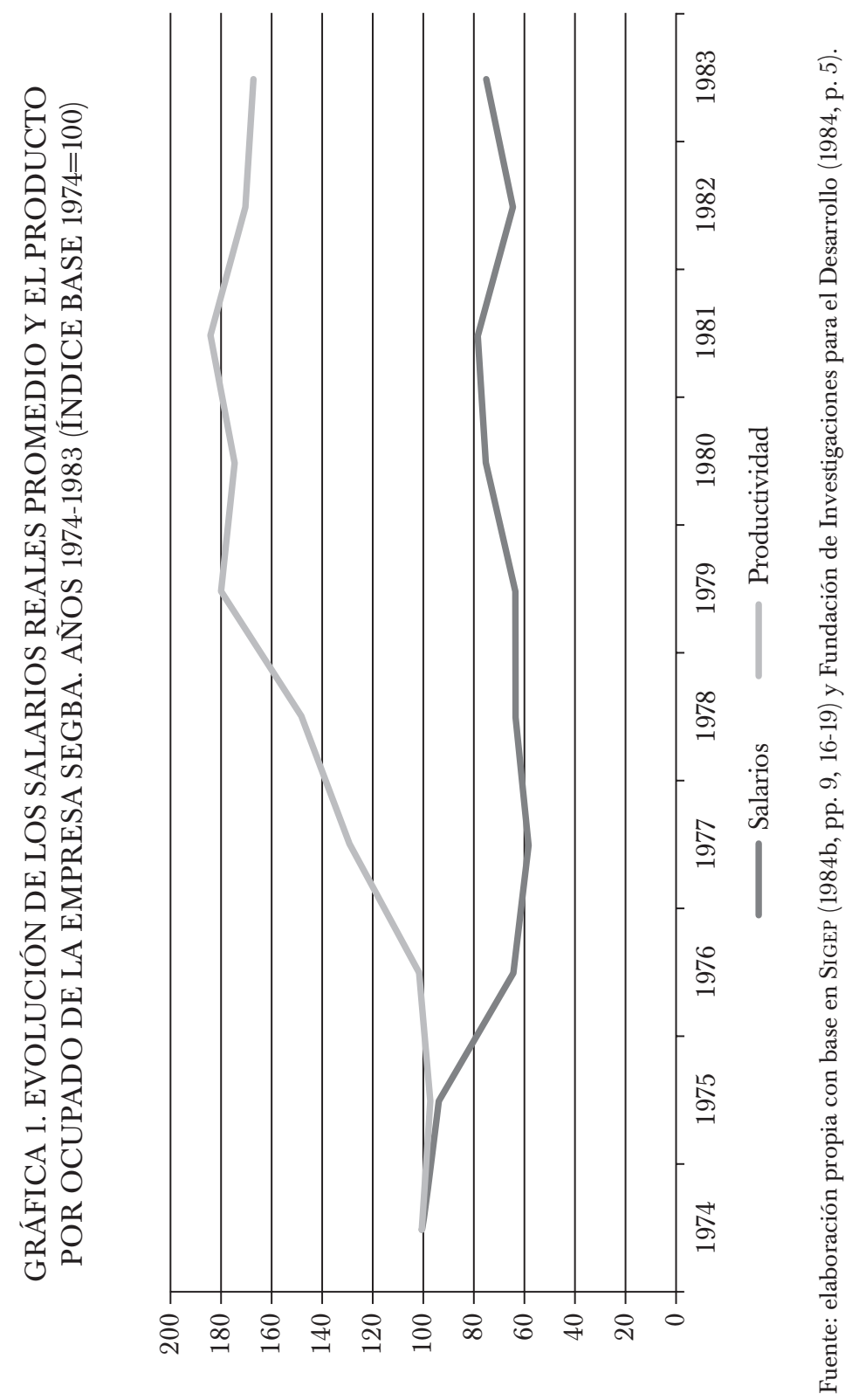




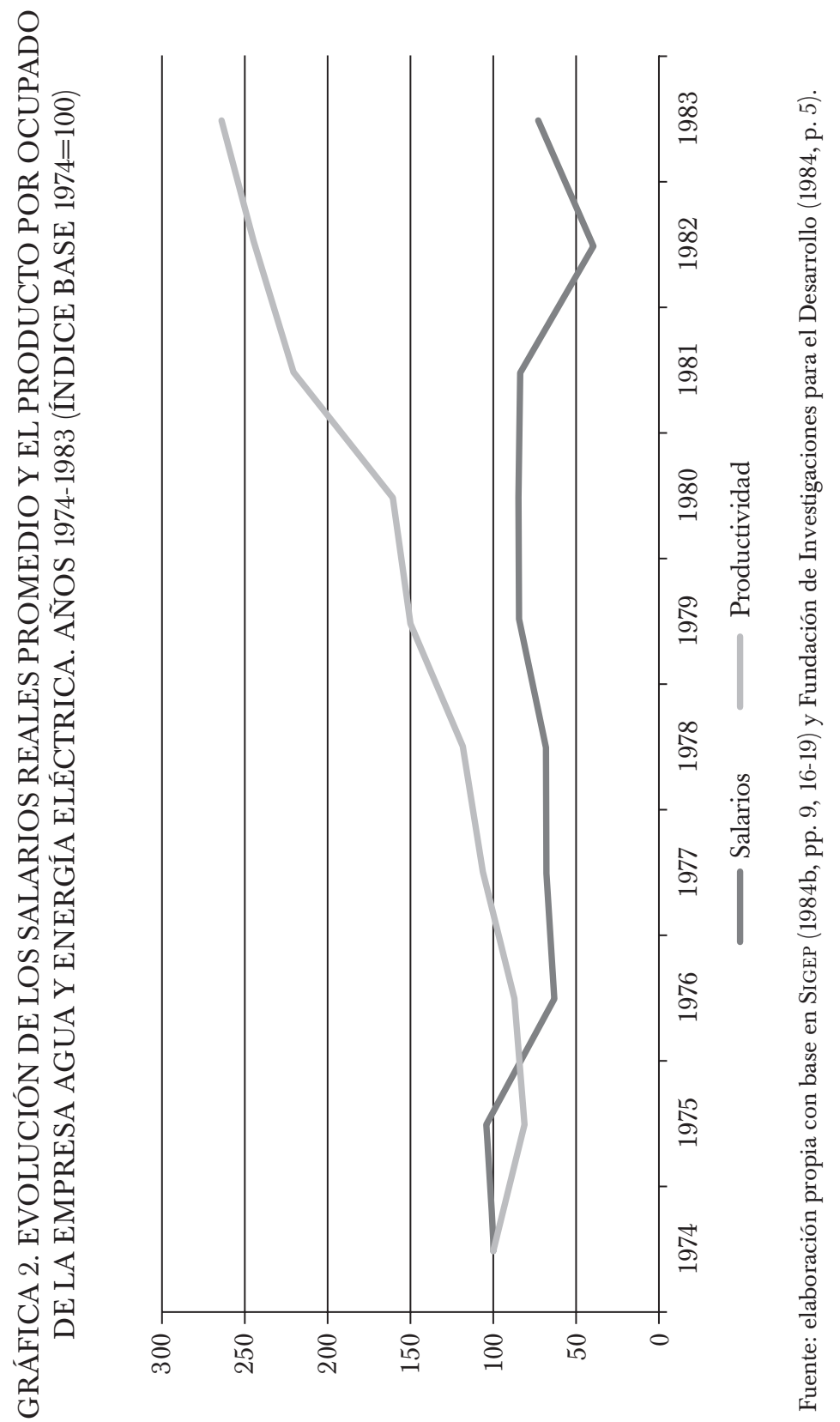




\section{CONCLUSIONES}

El análisis de desempeño de la muestra de empresas públicas argentinas más relevantes durante la última dictadura cívico-militar permite señalar algunas conclusiones preliminares.

Se produjo un fuerte ajuste en la dotación de personal en casi todas las firmas analizadas, excepto ENTEL y Gas del Estado, que también experimentaron un descenso en sus planteles laborales, pero de menor intensidad en relación con el resto de las firmas consideradas en el análisis.

Asimismo, se llevó a cabo un ajuste del salario real muy fuerte en los dos primeros años de la dictadura, como por ejemplo la caída de las remuneraciones en 1976 respecto al año anterior para YPF, Gas del Estado SEGBA, y AYEE, de 31, 25, 32 y 40\%, respectivamente. De manera análoga, en los casos de Ferrocarriles Argentinos, ENTEL y OSN, la disminución del salario real en 1976 en relación con 1975 fue de 24, 27 y 25 por ciento.

También se produjo un aumento de la productividad en todos los casos examinados. En efecto, el incremento del producto por ocupado en las empresas públicas fue muy significativo, tanto que en algunos casos (como el de la firma AYEE) la productividad entre 1974 y 1983 se expandió 163\%. En los otros casos, los incrementos, aunque sin alcanzar las cifras de AYEE, también fueron muy pronunciadas. Si se toman las variaciones de 19741983, se corrobora que el producto por ocupado de YPF, Gas del Estado, SEGBA, Ferrocarriles Argentinos, ENTEL y OSN, ascendió, respectivamente, $52,40,66,33,48$ y 71 por ciento.

Además, dicho incremento de la productividad ocurrió por una caída del salario real o de la cantidad de personal ocupado, o por ambos; lo cual constituye un indicador proxy de la intensificación en la explotación de la fuerza de trabajo y del concomitante aumento de los excedentes a disposición de las firmas estatales. No obstante, ello no indica que esos excedentes efectivamente se los hayan apropiado las empresas públicas, sino que, en muchos casos, fueron transferidos vía subsidios de diversa índole y/o tarifas y precios preferenciales en los bienes y servicios producidos por dichas firmas hacia el capital concentrado interno de la economía argentina.

Por otra parte, la inversión real fija tuvo un desempeño errático. Se registraron momentos de alzas y bajas, que incluso en algunos casos no correspondían a los avatares del ciclo económico. Ahora bien, si se toma como punto de referencia de la evolución de esta variable el periodo 19741983, se verifica, salvo el caso de ENTEL (crece 78\% a lo largo del periodo analizado) y Ferrocarriles Argentinos (disminuye apenas 1.4\% entre 1974 y 1983), un marcado descenso en los niveles de inversión. La caída más fuerte se registra en el caso de la firma AYEE, cuyos gastos de inversión 
mermaron en 55\% si se compara el año base 1974 con el año final de la serie que es 1983.

Por último, es necesario subrayar la clara evidencia de una política deliberada de endeudamiento externo de todas las empresas públicas que no muestra correlación con un aumento de la inversión real fija. Si se considera la evolución de la deuda externa de la muestra de firmas estatales analizadas aquí, entre 1978 y 1983, se constató, respectivamente, para YPF, Gas del Estado, SEGBA, AYEE, Ferrocarriles Argentinos y EnTEL, un incremento de sus pasivos externos de 237, 450, 77, 164, 269 y 361\%. Este abultado endeudamiento externo impactó negativamente en el desempeño de dichas firmas en los años posteriores y fue una de las causas que explican el deterioro sufrido en sus respectivas producciones de bienes y servicios, lo cual, a su vez, se utilizó en la década de 1990 como un argumento para legitimar ante la opinión pública sus supuestas ineficiencias intrínsecas y la necesidad de transferir las estratégicas empresas estatales a manos del sector privado en el marco de un acelerado y poco transparente proceso de enajenación del patrimonio estatal.

Estos primeros hallazgos deberán complementarse con estudios de más largo alcance que permitan establecer con claridad las tendencias en el desempeño de las empresas públicas argentinas desde 1960 hasta 1990, momento en el que la mayoría de ellas fueron privatizadas. De esta forma, se podría contar con un panorama más preciso del rumbo seguido por el Estado empresario argentino y de las continuidades y rupturas en las políticas públicas que se aplicaron para sostener o no el papel de las empresas estatales en el proceso de desarrollo.

Lamentablemente las dificultades para reconstruir series de datos de largo alcance con fuentes confiables impiden avanzar en estas líneas de investigación. Parte de las consecuencias del desmantelamiento del Estado empresario en Argentina, desde la dictadura hasta la década de 1990, es la destrucción de los archivos de las empresas públicas y esa carencia es uno de los principales obstáculos al encarar investigaciones más ambiciosas que permitan no sólo la descripción, sino la explicación de varios de los fenómenos que aquí se han esbozado.

En suma, el caso argentino invita a reflexionar sobre las graves consecuencias que las políticas de racionalización y modernización tienen sobre el desempeño de las firmas estatales y sobre el cuidado de las capacidades y los activos públicos construidos a lo largo de varias décadas. 


\section{LISTA DE REFERENCIAS}

ANDRIEU, P. (1975). Empresas públicas: el rol del Estado en el crecimiento económico y el cambio social. Buenos Aires: El Coloquio.

AzPiAzu, D., Basualdo, E. y KHAVISSE, M. ([1986], 2004). El nuevo poder económico en la Argentina de los años 80. Buenos Aires: Siglo XXI.

Banco Interamericano de Desarrollo (BID) (1983). Administración de empresas públicas (vol. 3). México: Autor/Escuela Interamericana de Administración Pública/ Fundação Getulio Vargas.

Barrera, M., Sabbatella, I. y Serrani, E. (2012). Historia de una privatización. Cómo y por qué se perdió YPF. Buenos Aires: Capital Intelectual.

Basualdo, E. (1987). Deuda externa y poder económico en la Argentina. Buenos Aires: Nueva América.

Basualdo, E. (2000). Acerca de la naturaleza de la deuda externa y la definición de una estrategia politica. Buenos Aires: Facultad Latinoamericana de Ciencias Sociales/ Universidad Nacional de Quilmes/Página 12.

Basualdo, E. (2010). Estudios de historia económica argentina. Desde mediados del siglo XX a la actualidad. Buenos Aires: Facultad Latinoamericana de Ciencias Sociales/Siglo XXI.

Belini, C. y Rougier, M. (2008). El Estado empresario en la industria argentina. Conformación y crisis. Buenos Aires: Manantial.

Bernal, F. (2005). Petróleo, Estado y soberanía. Hacia una empresa multiestatal latinoamericana de hidrocarburos. Buenos Aires: Biblos.

Bertino, M., Rímoli, P., Torrelli, M. y VÁzquez, D. (2011). Primera aproximación al estudio de los niveles de inversión en las empresas públicas uruguayas (19552010) en perspectiva comparada. Ponencia presentada en Quintas Jornadas de Historia Económica (pp. 1-24). Montevideo: Asociación Uruguaya de Historia Económica. Recuperado de http://www.audhe.org.uy/images/stories/upload/ponencia $\% 20$ inversiones $\% 20$ empresas $\% 20$ pblicas.pdf

Bleger, L. y GARCÍA, A. (1988). El Estado y las empresas públicas en la economía argentina. Rosario: Instituto de la Cooperación.

Boeninger, E. y Palma, E. (1978). Empresas estatales: el caso chileno y un análisis general. En Seminario sobre el proceso de planificación en América Latina y las empresas estatales (pp. 1-142). Lima: Comisión Económica para América Latina y el Caribe.

BoneO, H. (1980). Regímenes políticos y empresas públicas: algunas cuestiones vinculadas al ámbito y dimensión del sector productivo estatal. Estudios CEDES, 3(7), 1-33.

Boneo, H. (1988). Las empresas estatales en América Latina. Caracas: Centro Latinoamericano de Administración para el Desarrollo.

Canelo, P. (2008). El proceso en su laberinto. La interna militar de Videla a Bignone. Buenos Aires: Universidad Nacional de San Martín/Prometeo. 
CANElo, P. (2016). La política secreta de la última dictadura argentina (1976-1983). Buenos Aires: Edhasa.

Canitrot, A. (1983). Orden social y monetarismo. Cuadernos CEDES, 7(4), 5-50.

Casar, M. A. y Peres, W. (1988). El Estado empresario en México: ¿agotamiento o renovación? México: Siglo XXI Editores.

Castellani, A. (2004). Gestión económica liberal-corporativa y transformaciones en el interior de los grandes agentes económicos de la Argentina durante la última dictadura militar. En A. PUCCIARELLI (coord.), Empresarios, tecnócratas y militares. La trama corporativa de la última dictadura. Buenos Aires: Siglo XXI.

Castellani, A. (2009). Estado, empresas y empresarios. La construcción de ámbitos privilegiados de acumulación entre 1966 y 1989. Buenos Aires: Prometeo.

Chávez, D. y CoRTÉs, A. (2013). Una empresa pública excepcional en una socialdemocracia en crisis: el Instituto Costarricense de Electricidad. Revista de Gestión Pública, 2(1), 67-106. Recuperado de http://www.revistadegestionpublica.cl/Vol_ II_No_1/Chavez $\% 20 y \% 20$ Cortes.pdf

Centro latinoamericano para el Análisis de la Democracia (1991). Documentos sobre privatización con énfasis en América Latina: empresas públicas y políticas de privatización (Serie Infoplan. Temas especiales de desarrollo, 7-290, pp. 1-62). Santiago: Autor. Recuperado de http://repositorio.cepal.org/handle/11362/3293

Costa, A. D., Pessali, H. F. y Gonçalves, S. C. (2013). Petróleo Brasilero S. A.: una empresa estatal brasileña internacionalizada. Revista de Gestión Pública, 2(1), 183-213. Recuperado de http://www.revistadegestionpublica.cl/Vol_II_No_1/ Dalla $\% 20$ Costa $\% 20$ et $\% 20$ al.PDF

Costa, F. L. D. y Miano, V. Y. (2013). Estatização e desestatização no Brasil: o papel das empresas estatais nos ciclos da intervenção governamental no domínio económico. Revista de Gestión Pública, 2(1), 145-181.

Damill, M. y Frenkel, R. (1994). Restauración democrática y política económica [mimeo]. Buenos Aires: CEDES.

Di Tella, G. (1983). Perón-Perón. 1973-1976. Buenos Aires: Hyspamérica.

Fernández, R. (1976). Las empresas públicas en Argentina. Buenos Aires: Comisión Económica para América Latina y el Caribe.

Fundación de InVESTigaciones ECONÓmiCAs LatinOAMERICANAS [FIEL] (1987). El fracaso del estatismo. Buenos Aires: Sudamericana/Planeta.

Fundación de InVESTigaciones PARA El Desarrollo [FIDE] (1984). Coyuntura y desarrollo, Anexo Estadístico XVII. Buenos Aires: Autor.

GiLlis, M. (1980). The role of State enterprises in economic development. Social Research, 47(2), 248-289. Recuperado de http://www.jstor.org/stable/40982645

Guajardo, G. (2013). Empresas públicas en América Latina: historia, conceptos, casos y perspectivas. Revista de Gestión Pública, 2(1), 5-24. Recuperado de http://www. revistadegestionpublica.cl/Vol_II_No_1/Guajardo.pdf

Heredia, M. (2004). El proceso como bisagra. Emergencia y consolidación del liberalismo tecnocrático: FIEL, FM y CEMA. En A. PUCCIARELLI (coord.), Empresarios, 
tecnócratas y militares. La trama corporativa de la última dictadura. Buenos Aires: Siglo XXI.

Instituto Latinoamericano de Planificación Económica y Social [ilPes] (1981). Estilos de planificación y sistemas de empresas públicas en América Latina. Santiago de Chile: Autor.

JEAnnot, F. (1990). La modernización del Estado empresario en América Latina. Hacia una teoría del sector público. México: Universidad Autónoma Metropolitana.

Kaplan, M. (1965). Desarrollo económico y empresa pública. Buenos Aires: Macchi.

KozUlJ, R. y BRAVO, V. (1993). La política de desregulación argentina: antecedentes e impactos. Buenos Aires: Centro Editor de América Latina.

Larroulet, C. (1984). Reflexiones en torno al Estado empresario en Chile. Documento de trabajo del CEP, 22, 129-151. http://www.cepchile.cl/1_1488/doc/reflexiones_ en_torno_al_estado_empresario_en_chile.html\#.ViFayrV8pME

Marichal, C. (2011). Auge y declive de las empresas estatales en México: impactos de largo plazo de la crisis de los años 1980. Ponencia presentada en Quintas Jornadas de Historia Económica (pp. 1-23). Montevideo: Asociación Uruguaya de Historia Económica. Recuperado de http://www.audhe.org.uy/images/stories/upload/marichal $\% 20$ empresa $\% 20$ publica $\% 20$ p $\% 20$ montevideeo.pdf

Medellín, P. (1994). La modernización del Estado en América Latina: entre la reestructuración y el reformismo. Revista del CLAD Reforma y Democracia, 2, 1-30. Recuperado de http://old.clad.org/portal/publicaciones-del-clad/revista-clad-reformademocracia/articulos/002-julio-1994/0023100.pdf

Novaro, M. y Palermo, V. (2003). La dictadura militar 1976-1983. Buenos Aires: Paidós.

Organización de las Naciones Unidas [Onu]. Departamento de Cooperación Técnica para el Desarrollo (1989). Las empresas públicas mixtas en los países en desarrollo: organización, gestión y problemas fundamentales. Nueva York: Autor.

Pucciarelli, A. (2004). La patria contratista. El nuevo discurso liberal de la dictadura militar encubre una vieja práctica corporativa. En A. PuCCIARELLI (coord.), Empresarios, tecnócratas y militares. La trama corporativa de la última dictadura. Buenos Aires: Siglo XXI.

Quiroga, H. (2004). El tiempo del "Proceso". Conflictos y coincidencias entre políticos y militares 1976-1983. Rosario: Fundación Ross/Homo Sapiens Ediciones.

Rapoport, M. (2003). Historia económica, política y social de la Argentina (1880-2000). Buenos Aires: Macchi.

Regalsky, A. y Rougier, M. (2015). Los derroteros del Estado empresario en la Argentina. Siglo XX. Buenos Aires: Universidad Nacional de Tres de Febrero.

Rougier, M. (2009). ¿Elefante o mastodonte? Reflexiones sobre el tamaño del Estado empresario en la "edad de oro" de la industrialización por sustitución de importaciones en la Argentina. En A. Müller (comp.), Industria, desarrollo, historia. Ensayos en homenaje a Jorge Schvarzer. Buenos Aires: Universidad de Buenos Aires. 
SAulniers, A. (1985). Public enterprises in Latin America: The new look? ILAS Technical Paper, 44, 1-34.

SCHORR, M. (2004). Industria y nación. Poder económico, neoliberalismo y alternativas de reindustrialización en la Argentina contemporánea. Buenos Aires: Edhasa.

SchVarzer, J. (1979). Empresas públicas y desarrollo industrial en Argentina. Buenos Aires: Centro de Investigaciones Sociales sobre el Estado y la Administración.

SCHVARZER, J. (1981). Expansión económica del Estado subsidiario 1976-1981. Buenos Aires: Centro de Investigaciones Sociales sobre el Estado y la Administración.

Schvarzer, J. (1986). La política económica de Martínez de Hoz. Buenos Aires: Hyspamérica.

SIDICARO, R. (2004). Coaliciones golpistas y dictaduras militares: el "proceso" en perspectiva comparada. En A. Pucciarelli (coord.), Empresarios, tecnócratas y militares. La trama corporativa de la última dictadura. Buenos Aires: Siglo XXI.

SilenZI, A. (1978). Soberanía y petróleo: YPF y los contratos de explotación de petróleo. Buenos Aires: Centro de Estudio General Mosconi.

Silenzi, A. (1983). Claves para una política petrolera nacional. Buenos Aires: Theoría.

Sindicatura General de Empresas Públicas [Sigep] (1984a). Participación de las empresas públicas en la economía. Comparación internacional. Buenos Aires: Autor.

Sindicatura General de Empresas Públicas [Sigep] (1984b). Síntesis estadística anual de las empresas públicas, año 1983. Buenos Aires: Autor.

Sojo, A. (1984). Estado empresario y lucha política en Costa Rica. San José: Universitaria Centroamericana.

Solberg, C. (1986). Petróleo y nacionalismo en la Argentina. Buenos Aires: Hyspamérica.

Torrado, S. (2010). Modelos de acumulación, regímenes de gobierno y estructura social. En S. TORRADo (dir.). El costo social del ajuste (Argentina 1976-2002) (t. I). Buenos Aires: Edhasa.

Verbitsky, H. (2006). Robo para la corona. Los frutos prohibidos del árbol de la corrupción. Buenos Aires: Página/12/Sudamericana.

Vernon, R. (1980). State-owned enterprises in Latina America and Western Europe: A comparative analysis. Development Discussion Paper, 111, 1-32.

Yacimientos Petrolíferos Fiscales [yPF] (1984). Memoria y balance año 1983. Buenos Aires: Autor.

Zuleta, M. C. (2013). Horizontes, negociaciones y disyuntivas en los tratos de yacimientos petrolíferos fiscales bolivianos con yacimientos petrolíferos fiscales, 19371945. Revista de Gestión Pública, 1(2), 107-143.

\section{Otras fuentes}

Sindicatura General de Empresas Públicas [Sigep] (1982). Informe de la reunión de expertos en administración de empresas públicas en América Latina y el Caribe. Documentos de Divulgación, 1, 1-28. 